\title{
Agent Mediation and Management of Virtual Communities: A Redefinition of the Traditional Community Concept
}

\author{
G.M.P. O’Hare ${ }^{1}$, C. Sas $^{1}$, \& C.A. Byrne ${ }^{2}$ \\ ${ }^{1}$ Department of Computer Science, University College Dublin (UCD), \\ Belfield, Dublin 4, Ireland, \\ Gregory.OHare, Corina.Sas \{@ucd.ie\} \\ ${ }^{2}$ Department of Computer Science, Carlow Institute of Technology, \\ Carlow, Ireland. \\ Byrneca@itcarlow.ie
}

\begin{abstract}
This paper explores the evolution of the concept of community in the light of computer mediated immersive virtual environments. The traditional concept of community has become strained it its attempts to capture the evolving virtual community. We believe the concept of the virtual community is of paramount importance and examine the extent to which this is being redefined to cater for it. We examine the management and mediation of such environments and specifically the social process associated with the cohabited users. We advocate the use of multi-agent systems in delivering this functionality.
\end{abstract}

Keywords: Community, Virtual Community, Collaborative Virtual Environments (CVEs), Multi-Agent Systems (MAS).

\section{Introduction}

Within this paper we seek to explore the evolution of the community of the $21^{\text {st }}$ centuary. In particular we wish to examine the extent to which the historical definition of community is still relevant to the new internet and immersive communities of today. Much has been written about virtual environments but as yet the associated virtual community have received scant consideration. We believe that the virtual community is, in and of itself, possibly more important that the virtual world itself and that the management and nurturing of the associated social process is of paramount importance.

Section 2 will journey upon a retrospective look at the traditional meaning of community adopting a sociological perspective. Section 3 will attempt to identify the preeminent factors which influence the sense of community within immersive collaborative virtual environments. We then briefly reflect upon these factors within our on-going research projects. Section 5 offers some conclusions.

\section{A Sociological Definition of Community}

In sociological terms we trace the origins of the concept of community back to Durkheim. Central to Durkheim's theories is the desire to create well-organised, ordered, and harmonious societies so that individuals could contribute to a community and live their lives contentedly. For Durkheim, the causes of social and individual ill-health stem from Anomie - a lack of regulating norms- this was the scourge of modern society [Dur33].

Research has identified numerous facets, which contribute to the sense of community. The geographic connotation represents a legacy from former eras where community was very much grounded in a locality. Further to this there is the common functional purpose that invariably unites its members together with an emerging sense of belonging [Pla74]. Other factors that seem inextricably linked to the concept of community involve the benefit derivable to the individual member and the community at large, evolving relationships through synchronous communication, a personal sense of involvement together with the existence of regulatory norms. We seek out new answers to old questions of anomie and whether we require the development of a new type of social anthropology [Bil97] that can accommodate, as well as offer insights into, the new generation of cyber-communities. 
Plant [Pla74] defines community as "...both a unit of society as it is and to the aspects of that unit that are valued if they exist and desired in their absence". It is a commonly held belief that the idea of community involves the whole person, with people meeting in the totality of their social roles and not in a fragmented or segmented way. Interactions within a community take place within a web of inclusive ties. Arguably the founding concepts of the whole person have been eroded through the division of labour, and the development of mass urban society. The virtual community will certainly result in the further diffusion and dilution of these cornerstones, interacting in various fragmented guises.

\section{Key Virtual Community Descriptors}

Traditionally it was the evolving discipline of Computer Support for Collaborative Work (CSCW) [BS91] which first introduced new strains upon our definition of community. More recently with the development of immersive Collaborative Virtual Environments (CVEs) [BDD88] further strains have been placed upon this concept. We will now seek to identify four facets of such technologies that have a pivotal contribution to make to the evolving definition of community.

\subsection{Cooperation and Collaboration}

Phylogenetic development emphasises the need for cooperation, based on division of labour. The mutual dependence individuals develop, fosters organic solidarity [Dur33] which will be equally prevalent in both real and virtual communities. Consequently this will impact upon existing rules of cooperation and competition. Since collaboration relies on people sharing information [EGR91], the sharing of resources between several users is therefore pivotal in these new computer mediated environments.

In order to allow sharing, an important prerequisite is that of an awareness of self and others. An underlying correlation exists between focused collaboration and the level of awareness [Gav91]. The shared representations required by $\mathrm{CSCW}$ systems, might well benefit from social-facilitation [AS95]. Delineating this concept, McGrath [McG84] assessed that "the presence and behaviour of other people [...] help to define the meaning of situation for individuals and can have a powerful impact on his or her behaviour, attitudes or feeling in those situations".

\subsection{Awareness}

Dourish and Bellotti defined awareness as "an understanding of the activity of others, which provides a context for your own activity" [DB92]. According to Frecon [Fre98], peripheral awareness namely coworkers' awareness of "what others are doing in order to promote co-ordination between cooperative workers", is one of the key issues central to Computer Supported Cooperative Work. In his theory of situational awareness, Endsley proposed a three-stage definition, based on perception of relevant elements of the environment, comprehension of those elements and prediction of the states of those elements in the near future [End95].

Gutwin and Greenberg [GG99] identified the basic characteristics of awareness, which set it apart from other kinds of knowing. Thus, awareness involves knowledge about the spatio-temporal state of a given environment, which must be maintained in order to reflect the dynamics and continuous changes of that environment. This knowledge is available through people interacting with the system and is not a goal in and of itself, but rather emerges as a bi-product of achieving the main goals of the activity. Benford et al. [BF93] have built a spatial model of interaction in virtual environments based on properties of space (e.g. aura and nimbus), as the base for mediating interaction. Within the virtual space, partitioned function of these concepts, "awareness between objects in a given medium is manipulated via focus and nimbus" $[\mathrm{BF}+94]$.

In some particular situations, where the system complexity surpasses our cognitive abilities, awareness is called situation awareness [Gil95]. Since situational awareness is a multidimensional concept, involving both status and spatio-temporal issues, different authors have identified spatial awareness as being an important component, encompassed by situational awareness ([VK89], [FD90]), [End88]). As Draper assessed "spatial awareness is a general term that includes several aspects of performance including 
judgments of the participant's position relative to the world and judgments of the relative positions of objects in the world " [Dra95].

Awareness of others can be facilitated through embodiment where it is viewed as a technologically extended body [Bio97], [Fre98].

\subsection{Embodiment}

Arguably the most important concept in engendering a sense of identity and consequently that of community within virtual reality systems is that of embodiment. The commissioning of avatars as a vehicle for embodiment raises interesting philosophical issues. The term avatar, borrowed from Hinduism where it means an incarnation of a deity, acts as a conduit for identity and communication within virtual environments [NB99]. Thus the avatar can be considered as being an interface through which the individual can exercise direct control, and through which it can influence the environment. Avatars have become increasingly photorealistic offering greater personalisation of the form and nature of the avatar coupled with heightened realism in terms of animation and character development. Benford stressed the dual role such avatars play in delivering both a sense of presence to the individual and to others [BB+95]. The avatar can sometimes even take on an existence that is considered beyond that of its mere user. It is however, clearly inseparable from that of its host, the human user. Little [Lit99] emphasises the idea of the avatar as an "imaged prosthesis of its referent - the user, and so is fundamentally related to linguistic signs and representational icons".

An interesting issue is the level to which users identify with the avatar, with all the psychological associations on body schema or body image [Bio97]. As Jackson highlighted [JL00], users are beings with diverse identities, and the embodiment plays a vital role in understanding them. The embodiment is more than just material body, but it also carries a gendered, social, political and economic identity. One of the most common psychological effects of embodiment is the rendering of a sense of presence [Bio97]. Nowak and Biocca [NB99] stressed the importance of body in achieving a sense of place, space and of another person's presence.

\subsection{Presence}

According to Biocca [Bio97] the sense of "being there", in the physical environment consists of "a basic state of consciousness in which the user attributes the source of the sensation to the physical environment". Durlach and Slater [DS00], regard presence as the sense of being with someone or the general sense of togetherness.

Togetherness, co-presence and social presence are all socially derived concepts, grounded on presence. Copresence is a notion, which enlarges the borders of presence, involving in addition the feeling that one is in the same spatio-temporal virtual environment with other users and where interaction is also possible. An important feature of co-presence consists of mental connection, which enable individuals to be aware not only one of the other, but also all of the common activity which takes place in the virtual space [NB99]. In a multi-user context, the individual can achieve a sense of social presence, namely the degree to which a user feels access to the intelligence, intentions, and sensory impressions of cohabitants. As IJsselsteijn et al. noticed, although the terminology used by various authors tends to vary, the term 'co-presence' has been suggested to refer to the mix of social and physical presence, i.e. a sense of "being there together" [IR +00$]$.

Lombard and Ditton's [LD97] grouped presence conceptualisations in two dimensions, namely physical and social presence. The physical presence is concerned with the sense of being physically located somewhere, while the social dimension underlies the feeling of being together with someone. One of the distinctive features of social presence consists of the awareness of another presence and the possibility of communicating and interacting with them.

\section{The Virtual Community}

The traditional definition of community is continually being challenged and stretched with the advent of such immersive technologies as CVEs, Collaborative Virtual and Augmented Environments [BMS97, 
BMS00], CAVES and fully immersive systems like blue-c [Sta00]. These technologies blur the traditional separation and distinction between the physical and the virtual.

The virtual community offers many similarities to that of its physical counterpart. Traditional communities have a strongly shared sense of belonging. The social science community however contest that in order to achieve a comparable sense of belonging in the virtual environment this necessitates that the individuals use their imagination. Therefore virtual communities must exist in the minds of their members through the medium of imagination if they are to exist at all [Rhe93]. The degree of imagination demanded is perhaps not that great. The blue-c project for example [Sta00], seeks to achieve even greater levels of user immersion supporting full immersion within a world through real time integration of human representations using large screens and cutting edge projection technologies. In addition the three dimensional human

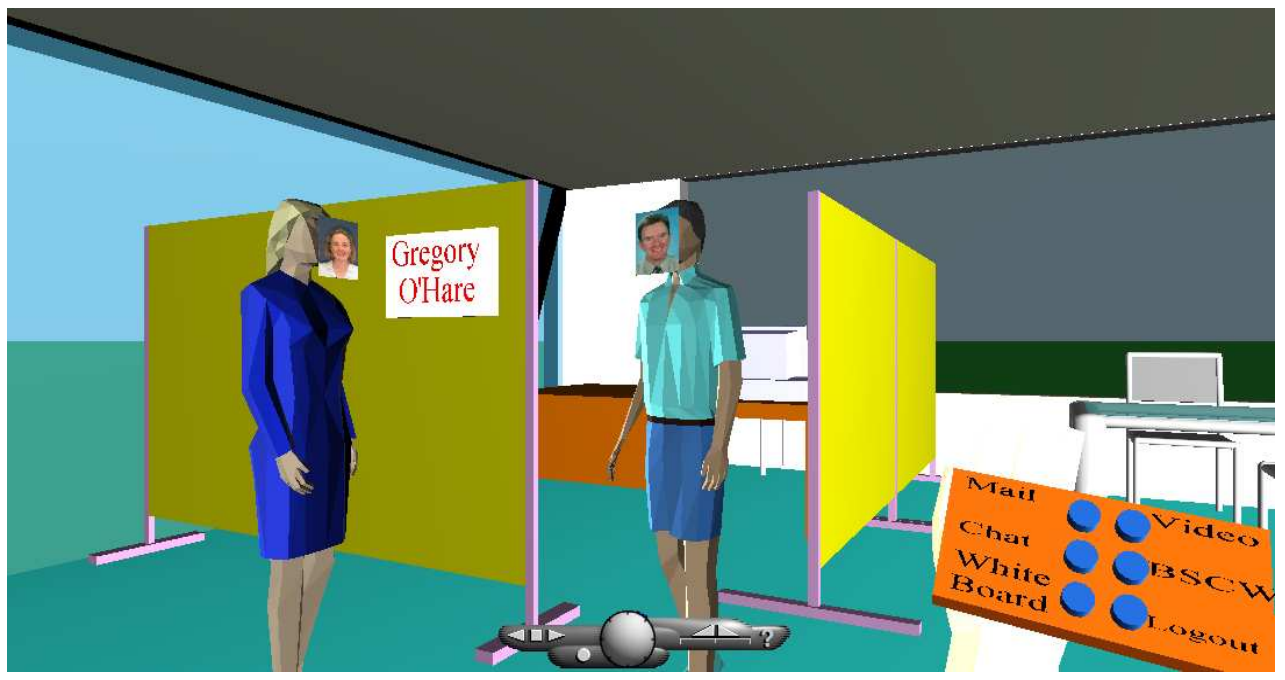

Figure 1: A Cohabited View of the ECHOES Collaborative Virtual Environment

in-lays support real time speech and motion together with novel interaction metaphors for interacting with fellow users and artifacts. It is often felt that virtual communities are transient, fragile and superficial and susceptible to disruption. To this ends we have sought to deploy agent-based techniques in the management and mediation of the virtual community and the underlying social structure, which this demands. Two such projects are those of ECHOES ${ }^{1}$ and ENTER ${ }^{2}$. The main objective of the (Educational Hypermedia On-linE System) ECHOES the (Educational Hypermedia On-linE System) project [PSO99, OMD99, OS+00] was to build a distributed dynamic environment for educating and supporting technicians in the use and maintenance of complex industrial artifacts. The ENTER project (ENvironment which Totally Envelops the useR ) [GOD00] sought to provide a totally immersive 3-Dimensional e-commerce environment which was highly configurable and personalisable based on the perceived needs of the individual user. Both such systems embraced an agent oriented approach to the mediation and management of the environment. Both systems present personalized and contextualised content based upon simple user profiles. Agents were employed to accrue user navigation and interaction data, filter this data and subsequently transform the quantitative data into qualitative data that could be used in the dynamic update of the user profiles. Figure 1 depicts a cohabited scene from the ECHOES environment. Here we see three users two in view of the third.

\footnotetext{
${ }^{1}$ ECHOES (European Project Number MM1006) is partially funded by the Information Technologies, Telematics Application and Leonardo da Vinci programmes in the framework of Educational Multimedia Task Force.

2 ENTER (Environment which Totally Envelops the user) has been supported through a Enterprise Ireland Applied Research Grant No. ARP/96/117.
} 


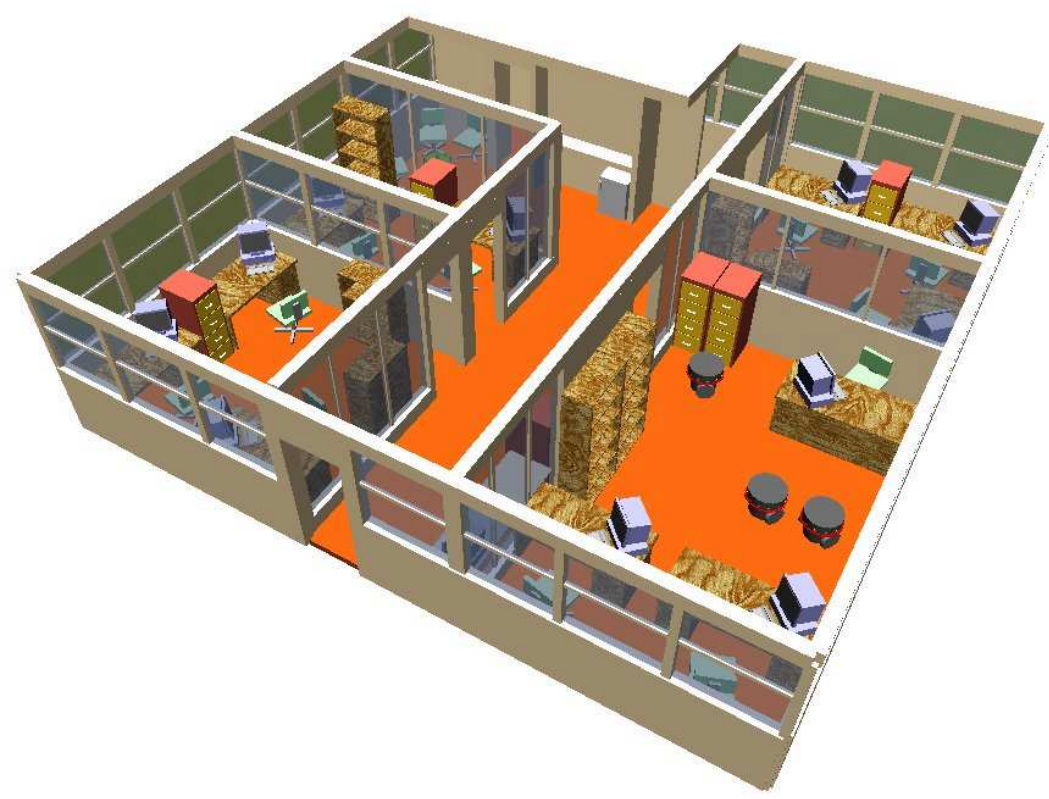

Figure 2: A Virtual Environment Cohabited with Virtual Social Robots

The viewing user is visible only through the virtual PDA (Personal Digital Assistant) shown in the foreground. User avatars can be personalized within the ECHOES environment at present we merely place a face gif in front of the selected avatar, though polygonal wrap functions would be preferable. We wish to stress that whilst the traditional community is comprised merely of humans, virtual communities may be comprised of a federation of virtual entities, avatars, robots and intelligent, though stationary objects. Figure 2 illustrates a virtual world with three virtual robotic entities situated within this. The IMPACT project $^{3}$ investigates social robotics and the use of multi-agent systems techniques in the control of federations of collaborating robots which operate within actual or virtual environments, thus offering yet another dimension to our future communities [DCO+99].

It is our conjecture that Durkheim's theory of anomie may be remodeled and recast in a manner amenable to computer mediated communities. To this ends we are utilizing agents in the overseeing and management of the social process synonymous with the virtual community. Agents assist in the identification and development of norms, imposing restrictions on freedom of expression and agreeing terms of imaginary engagement to mention but a few.

Our current work utilizes Agent Factory [OA95], [OJ96] a rapid prototyping environment for multi-agent systems developed at UCD, which renders the necessary Belief Desire Intention (BDI) apparatus for our agent operation. A duality exists whereby two contrasting social communities exist. The virtual user community within the immersive world and the community of collaborating agents that support the management of the social process associated with this community. The latter community similarly interacts and has a shared goal and purpose, together with, individual agent goals. The agents again have a self awareness and an awareness of colleagues achieved through the mental models of self and others. This is akinned to the Novak and Biocca's concept of co-presence. Exactly analogously agent relationships evolve and the authority relationships between agents may vary depending on the particular task context reflecting the dynamic workgroup structures witnessed in work organizations. We have already investigated the use of conversational structures as higher level regulators for agent interactions.

\footnotetext{
${ }^{3}$ This work has be conducted under Enterprise Ireland grant SP/97/08 IMPACT (Initiative for Mobile Programmable Agent-based Computing Technologies).
} 


\section{Conclusions}

Having catapulted ourselves from agricultural to post-modern society, the idea of community has evolved from the existence of shared norms and values, to contemporary society where a lack of norms feeds the existence of the virtual community one borne from the immersive cohabited virtual environments

Each community exists whether tangible or imaginary. The virtual community exhibits some of the characteristics of the traditional community including a sense of presence, awareness, a sense of belonging, perceived benefit and so forth but offers opportunities not available in its real counterpart, asynchronous communication, deception, geographic and temporal dispersal and multiple characters associated with the same individual. The virtual community offers the disabled, the marginalised, and the excluded in our traditional world an anonymity that allows them to participate equally in the imaginary community.

The virtual community does exist, not in the strict sense of the founding sociologists interpretation, but it exists nonetheless. However it is unregulated and its members sometimes deceived due to the fact that our traditional methods of scrutinising new members entering our social circle cannot be enforced. It is our belief that agent based approaches offer an elegant and pragmatic way to introduce and enforce these social norms. Furthermore an interesting duality exists between the social dynamics of members of the virtual community and the agents that support their social process.

\section{References}

[AS95] Ackerman, M. and Starr, B. Social Activity Indicators: Interface components for CSCW systems. ACM Symposium on User Interface Software and Technology. pp.159-168. 1995.

[BBD88] Bannon, L., Bjørn-Andersen, N., Due-Thomsen, B. Computer Support for Cooperative Work: An Appraisal and Critique. In Proceedings EURINFO 88 - Information Technology for Organizational Systems, pp 297-303 (Amsterdam: North-Holland). 1988.

[BS91] Bannon, L. and Schmidt, K. CSCW: Four Characters in Search of a Context. In J. Bowers \& S. Benford (Eds.) Studies in Computer Supported Cooperative Work: Theory, Practice and Design. Amsterdam North-Holland, pp 3 -16. 1991.

[BB+95] Benford, S. D., Bowers, J., Fahlen, L.E., Greenhalgh, C., Snowdon, D. User Embodiment in Collaborative Virtual Environments. ACM Conference on Human Factors in Computing Systems (CHI'95), ACM Press, Addision Wesley, pp242-249. 1995

[BF93] Benford, S.D, and Fahlén, L.E. A Spatial Model of Interaction in Large Virtual Environments. In Proc. Third European Conference on CSCW (ECSCW'93), Milano, Italy, Kluwer. 1993

[BF+94] Benford, S.D., Fahlen, L., Greenhalge, C., Bowers, J. Managing mutual awareness in collaborative virtual environments. In Proceeding ACM SIGCHI conference on Virtual reality and technology (VRST'94), ACM Press, Singapore. 1994.

[Bi197] Bilton, T., et al. (1997 ). Introductory Sociology . London: MacMillan Press.

[Bio97] Biocca, F. Cyborg's dilemma: Progressive embodiment in virtual environments. Journal of Computer Mediated-Communication, 3 (2). 1997.

[BMS97] Broll, W., Meier, E., Schardt, T.: "The Mixed Reality Stage". CAA Proceedings of the ACM SIGGRAPH 2000, 27th International Conference on Computer Graphics and Interactive Techniques, (New Orleans, USA, July 23-28, 2000), ACM, New York, 2000, p. 231 Scalable

[BMS00] Broll, W., Meier, E., Schardt, T.: "The Virtual Round Table - A Collaborative Augmented Multi-User Environment". Proc. of ACM CVE 2000: The 3rd Inter'l Conf. On Collaborative Virtual Environments, E Churchill, M. Reddy (eds.), ACM, New York, 2000, pp. 39-46

[DB92] Dourish, P. and Bellotti, V. Awarenss and Coordination in Shared Workspaces. Proceedings of Conference on Computer-Supported Cooperative Work, pp.107-114. 1992.

[Dra95] Draper, M. Exploring the influence of a virtual body on spatial awareness. Master's Thesis, University of Washington, College of Engineering. 1995.

[DCO+99] Duffy, B.R., O'Hare, G. M. P., O'Donoghue, R.P.S., Rooney, C.F.B., Collier, R.W., "Reality and virtual reality in mobile robotics", 1st International Workshop on Managing Interactions in Smart Environments MANSE'99, Dublin, December 1999, Springer-Verlag

[Dur33] Durkheim, E. The Division of Labor in Society Translated by George Simpson. New York: The Free Press. 1933. 
[DS00] Durlach, N and Slater, M. ) Presence in Shared Virtual Environments and Virtual Togetherness. In Presence: Teleoperators and Virtual Environments. 9(2), 2000.

[EGR91] Ellis, C.A., Gibbs, S.J., Rein, G.L. Groupware: Some Issues and Experiences, CACM 34(1), pp 38-58. 1991.

[End88] Endsley, M. Design and evaluation for situation awareness enhancement. Proceedings of the Human Factors Society 32nd annual Meeting, pp. 97-101. 1988.

[End95] Endsley, M. Toward a Theory of Situation Awareness in Dynamic Systems, Human Factors, 37(1), pp.32-64, 1995.

[FD90] Fracker, M.L. and Davis, S.A. Measuring operator situation awareness and mental workload. Proc. of the 5th Mid-Central Ergonomics/Human Factors Conf. Dayton, OH, 1990.

[Fre98] Frécon E. Actively Supporting Collaborative Work in Telepresence and Shared Virtual Environments Special Issue Earnshaw Rae (Ed.). 3(2), 1998.

[Gav91] Gaver, W.W. Sound Support for Collaboration. Proceedings of the Second European Conference on Computer Supported Cooperative Work ECSCW'91, Amsterdam, The Netherlands, Kluwer Academic Publishers, Dordrecht, pp. 293-308. 1991.

[Gil95] Gilson, R.D. Introduction to the Special Issue on Situation Awareness, Human Factors, 37(1), pp. 3-4, 1995.

[GG99] Gutwin, C. and Greenberg, S. A Framework of Awareness for Small Groups in SharedWorkspace Groupware. Technical Report 99-1, Department of Computer Science, University of Saskatchewan, Canada. 1999 http://www.cpsc.ucalgary.ca/grouplab/papers/

[GOD00] Guinan, T., O'Hare, G.M.P. \& Doikov, N. (2000). ENTER: The Personalisation and Contextualisation of 3-Dimensional Worlds. In Proc. of Eight Euromicro Workshop on Parallel and Distributed Processing (EURO-PDP 2000). pp. 142-149. IEEE Computer Society Press

[IR+00] IJsselsteijn, W. A., de Ridder, H., Freeman, J., Avons, S.E. Presence: Concept, determinants and measurement. Proc. of SPIE, Human Vision and Electronic Imaging V, 3959-76. 2000.

[JL00] Jackson, C. and Lalioti, V. Virtual Cultural Identities. CHI-SA, Human Computer Interaction in South Africa, in co-operation with ACM SIGCHI, University of Pretoria, 2000.

[Lit99] Little, G. A Manifesto for Avatars. INTERTEXTS, Special Issue: Webs of Discourse: The Intertextuality of Science Studies, 3(2). 1999.

[LD97] Lombard, M., \& Ditton, T. B. At the heart of it all: The concept of presence. Journal of Computer-Mediated Communication, 3(2). 1997.

[McG84] McGrath, J. Groups: Interaction and Performance. Prentice Hall, Englewood Cliffs, NJ, 1984.

[NB99] Nowak, K. and Biocca, F. I think there is someone else here with me!: The Role of the Virtual Body in the Sensation of Co-presence with Other Humans and Artificial Intelligences in Advanced Virtual Environments. In Proc., 3rd Annual Cognitive Technology Conference, pp. 291-302. 1999.

[OA95] O'Hare, G.M.P. and Abbas, S., "Commitment Manipulation within Agent Factory”, Proc. of Decent. Intel. \& MAS, Cracow, Poland, 1995

[OJ96] O'Hare, G.M.P. and Jennings, N.R. (Editors.), Foundations of Distributed Artificial Intelligence, Wiley Interscience Pub., New York, 1996, 296 pages. ISBN 0-471-00675

[OMD+99] O'Hare, G.M.P., Murphy A., Delahunty, T., Sewell K., ECHOES: A Collaborative Virtual Training Enviornment, TWLT 15 Interactions in Virtual Worlds (eds. Nijholt, A., Donke, O., Van Dijk, B.), Proceedings of $15^{\text {th }}$ TWENTE Workshop on Language Technology, Enschede, The Netherlands, 1999.

[OS+00] O’Hare, G.M.P., Sewell, K. Murphy, A. ,Delahunty, T., ECHOES: An Immersive Training Experience, In Proceedings of the International Conference on Adaptive Hypermedia and Adaptive Web-based Systems, (Adaptive HyperMedia 2000), Trento, Italy.

[Pla74] Plant, R., (1974). Community and Ideology. London: Routledge \& Kegan Paul.

[PSO00] Pasquarelli A., de Stefani, F., O'Hare, G.M.P. Murphy, A. J., ECHOES: EduCational Hypermedia On-linE System, Proceedings of IEEE MultiMedia Conference, Firenze, Italy June 19th-21st 1999

[Rhe93] Rheingold, H.(1993). The Virtual Community. Reading, MA: Addison-Wesley Publishers.

[Sta00] O. G. Staadt, A. Kunz, M. Meier, M. H. Gross: The Blue-C.: Integrating Real Humans into a Networked Immersive Environment. Proc. of ACM Collaborative Virtual Environments 2000, pp. 201-202, ACM Press.

[VK89] Venturino, M. and Kunze, R.J. Spatial awareness with a helmet-mounted display. Proceedings of the Human Factors Society 33rd Annual Meeting, pp.1388-1391. 1989. 